\title{
Germinação de sementes de Aspidosperma subincanum Mart. ex A. DC em diferentes temperaturas
}

OLIVEIRA, A.K.M. ${ }^{*}$; CARVALHO, J.M.B.2; SOUZA, J.S.2; SOUZA, S.A. ${ }^{2}$

Universidade Anhanguera-Uniderp, Programa de Pós-Graduação em Meio Ambiente e Desenvolvimento Regional, Rua Alexandre Herculano, 1400 - Jardim Veraneio, CEP 79037-280, Campo Grande, Mato Grosso do Sul; 2Universidade Anhanguera-Uniderp, Curso de Ciências Biológicas, Rua Alexandre Herculano, 1400 - Jardim Veraneio, CEP 79037-280, Campo Grande, Mato Grosso do Sul. *Autor para correspondência: akmorbeckoliveira@gmail.com

RESUMO: Aspidosperma subincanum é uma espécie arbórea utilizada em projetos de recuperação de áreas degradadas e como planta medicinal. Levando-se em consideração a importância da espécie, o presente trabalho teve como objetivo definir a temperatura ideal para a germinação de suas sementes. O material vegetal foi coletado na região do Pantanal de Miranda, Mato Grosso do Sul. As sementes foram colocadas em caixas plásticas transparentes em câmara de germinação e submetidas às temperaturas constantes de $20,25,30$ e $35^{\circ} \mathrm{C}$ e alternadas de $20-30$ e $25-35^{\circ} \mathrm{C}$. O delineamento experimental foi inteiramente casualizado, com quatro repetições por tratamento, sendo as médias comparadas pelo teste de Tukey a $5 \%$. A temperatura ideal para a germinação de Aspidosperma subincanum foi a $25^{\circ} \mathrm{C}$, com o maior índice de velocidade de germinação, 18,8. Temperaturas mais elevadas $\left(30\right.$ e $\left.35^{\circ} \mathrm{C}\right)$ causaram a morte dos embriões.

Palavras-chave: Pantanal, crescimento de plântulas, guatambu

\begin{abstract}
Germination of Aspidosperma subincanum Mart. ex A. DC seeds at different temperatures. The Aspidosperma subincanumem is a tree species used in the recovery of degraded areas projects and as a medicinal plant. Taking into account the importance of the species, the current study aimed to determine which would be the ideal temperature for the germination of their seeds. The plant material was collected in the Pantanal of Miranda, Mato Grosso do Sul. The seeds were placed in transparent boxes in germination chambers and submitted to constant temperatures of, $20,25,30$ and $35^{\circ} \mathrm{C}$ and alternated at 20-30 and 25$35^{\circ} \mathrm{C}$, with four replicates per treatment. The statistical design was a completely randomized one. The averages were compared by Tukey test at $5 \%$. The ideal temperature for germination of Aspidosperma subincanum was $25^{\circ} \mathrm{C}$. The high temperatures $\left(30\right.$ and $\left.35^{\circ} \mathrm{C}\right)$ have caused the death of embryos.
\end{abstract}

Keywords: Pantanal, seedling growth, guatambu.

\section{INTRODUÇÃO}

A espécie Aspidosperma subincanum Mart. ex A. DC, conhecida popularmente como guatambu, perobinha ou pereiro, pertencente a família Apocynaceae, ocorre principalmente na região de florestas latifoliadas nos Estados de São Paulo, Minas Gerais, Mato Grosso, Mato Grosso do Sul e Goiás. As árvores desta espécie podem alcançar altura entre 15-20 m, possuem madeira dura, resistente, utilizada na construção civil e também em projetos de recomposição de áreas degradadas, entre outros usos (Lorenzi, 2008).

$\mathrm{Na}$ medicina popular, possui ampla utilização, com pesquisas relatando que a espécie é utilizada no combate do diabetes e da hipercolesterolemia (Tresvenzol et al., 1997) e no tratamento de problemas associados ao aparelho digestivo (Monteles \& Pinheiro, 2007).

Pesquisas realizadas em laboratório, em modelo de hiperlipidemia induzida por Triton WR 1339 em camundongos, demonstram que a espécie foi ativa, reduzindo o nível de triglicérides sérico em $41 \%$, quando comparado aos animais normais (Silva, 2009). Em outro estudo, Santos et al. (2009) indicaram a dose segura para seres 
humanos em $210 \mathrm{mg} / 70 \mathrm{~kg} / \mathrm{dia}$, além de demonstrar nas cascas do caule a presença de alcalóides, saponinas, terpenóides, esteróides e taninos, além do isolamento de ácido oleico e guatambuine. Em estudos com extrato etanólico da espécie, Bernardes et al. (2013) encontraram indicações que o mesmo induz a hipotensão associada à bradicardia, além de levar ao relaxamento vascular endotélio-independente.

Desta maneira, a obtenção de mudas desta espécie pode contribuir para o aproveitamento de seus princípios ativos através do cultivo, além de oferecer opções para o uso em programas de silvicultura. Porém, a utilização de espécies nativas nestes programas silviculturais muitas vezes é dificultada pelo pouco conhecimento de suas características ecológicas. Assim, o estudo das condições mais adequadas para sua germinação torna-se importante.

Existem diversos fatores que comumente afetam a germinação, sendo eles as condições climáticas predominantes durante a maturação, condições de armazenamento, tamanho e idade das sementes, disponibilidade de água e temperatura durante a embebição, entre outros (Carvalho \& Nakagawa, 2012).

Pesquisas sobre o efeito desses fatores no desenvolvimento de sementes de espécies florestais nativas do Brasil vêm sendo continuamente publicadas e o estudo de condições controladas dos três principais fatores, luz, temperatura e umidade, testadas para diferentes espécies, em laboratório e campo (Piña-Rodrigues et al., 2004). Dentre esses fatores, a temperatura mais adequada auxilia na germinação, por afetar as reações bioquímicas e a velocidade de absorção de água, que interferem em todo o processo germinativo (Carvalho \& Nakagawa, 2012) e por este motivo, pesquisas com este fator são comumente realizadas.

Porém, não existe uma temperatura padrão para todas as espécies. As plantas nativas brasileiras podem germinar em uma ampla faixa térmica, dependendo do bioma e da região, com a maioria das espécies apresentando o melhor desempenho germinativo entre 20 a $35^{\circ} \mathrm{C}$ (Larcher, 2003; Brancalion et al., 2010).

Levando-se em consideração a pequena quantidade de informações sobre as melhores condições para a germinação dessa espécie, este trabalho foi desenvolvido com o objetivo de estudar a temperatura ideal para a germinação, utilizando-se sementes de $A$. subincanum coletadas em áreas do Pantanal de Miranda, Mato Grosso do Sul.

\section{MATERIAL E MÉTODO}

Foram coletados frutos de 15 árvores matrizes, com características semelhantes, distantes entre si mais de 50 metros, localizadas no Pantanal de Miranda, Município de Miranda, Mato Grosso do Sul, na fazenda Baia Grande (S 20.40925", W 056.34840"), $121 \mathrm{~m}$ de altitude, em outubro de 2011. Após a coleta, foram acondicionados em sacos de papel e transportados ao Laboratório de Pesquisa em Sistemas Ambientais e Biodiversidade, Universidade Anhanguera-Uniderp, Campo Grande, Estado de Mato Grosso do Sul, sendo as sementes retiradas dos frutos, que possuíam, em média, seis sementes. As mesmas foram selecionadas, eliminando-se as chochas e atacadas por insetos; após a triagem, o teor de água das sementes foi determinado por meio do método de estufa a $105 \pm$ $3^{\circ} \mathrm{C}$, conforme Brasil (2009).

As sementes selecionadas para o teste de germinação foram desinfestadas em solução hipoclorito de sódio (2\%) por cinco minutos, sendo, em seguida, lavadas em água corrente por um minuto, tendo suas alas retiradas para facilitar a acomodação nas caixas. Para a avaliação do efeito da temperatura sobre a germinação, foram utilizadas as temperaturas constantes de 20,25 , 30 e $35^{\circ} \mathrm{C}$ e alternadas de $20-30$ e $25-35^{\circ} \mathrm{C}$, com quatro repetições de 25 sementes por tratamento e fotoperíodo de $12 \mathrm{~h}$ de luz branca (quatro lâmpadas fluorescentes de $20 \mathrm{~W}$ ) em câmaras de germinação. Os testes foram conduzidos em caixas plásticas transparentes $(11 \times 11 \times 3,5 \mathrm{~cm})$ sobre duas folhas de papel germitest previamente umedecidos em uma solução tendo como base o fungicida Rovral a $0,1 \%(\mathrm{~m} / \mathrm{v})$, com volume da solução equivalente a 2,5 vezes a massa do papel não hidratado.

O delineamento experimental foi o inteiramente casualizado, avaliando-se a percentagem de germinação, de acordo com a fórmula de Borghetti \& Ferreira (2004) e o vigor das sementes, medido indiretamente pelo tempo médio de germinação em dias (TMG), quantificando a germinação sob o ponto de vista cinético (Labouriau \& Agudo, 1987) e pelo índice de velocidade de germinação (IVG) (Maguire, 1962). Para avaliação dos resultados de germinação (\%), IVG e TMG, foi utilizado o programa estatístico Assistat 7.7 beta, não sendo necessária a transformação dos dados de germinação, IVG e TMG. Também foi realizada uma regressão polinomial para as temperaturas constantes, com obtenção do valor da temperatura ideal, obtido através de uma adaptação da fórmula de Bhaskara, com equação $y=-12 x^{2}+29,4 x+72$ e, $R^{2}=0,9786$.

Foram consideradas germinadas as sementes que apresentavam protrusão de raiz

Rev. Bras. PI. Med., Campinas, v.17, n.4, p.642-648, 2015. 
primária de $2 \mathrm{~mm}$. Nas sementes não germinadas, seguindo procedimentos de Brasil (2009), realizouse o teste de viabilidade de tetrazólio (sal trifenilcloreto de tetrazólio a $1 \%$ em solução aquosa); as sementes foram acondicionadas em caixas de plástico escuras, colocadas entre duas folhas de papel toalha umedecidas, em temperatura de $25^{\circ} \mathrm{C}$ por um período de 24 horas, com a solução. Após este período de embebição, as sementes sofreram um corte longitudinal, deixando o embrião exposto e possibilitando a visualização da coloração através de estereomicroscópio. A verificação da presença de carboidratos nas sementes foi feita através de reação química utilizando-se lugol [I2 (1\%) + KI $(2 \%)]$, em que a cor roxa indicava a presença desta estrutura de armazenamento.

\section{RESULTADO E DISCUSSÃO}

O teor de água nas sementes recémcolhidas, um dado importante na execução dos testes, considerando-se que a uniformização do teor de água das sementes é importante para os estudos de avaliações e obtenção de resultados consistentes, foi de $4 \%$. De acordo com Bewley \& Black (1994), este valor é ligeiramente inferior ao normalmente encontrado para a maior parte das espécies vegetais, entre 5 e $20 \%$.

Dados publicados por Salomão et al. (2003) indicaram que as sementes da espécie possuem o teor inicial de água de 7\%, similar ao encontrado para outras espécies do mesmo gênero, tais como A. discolor A. DC. (5,8\%), A. macrocarpon Mart. (6 a
$10 \%)$ e A. parvifolium A. DC. (7,3\%), indicando que as sementes desse gênero normalmente possuem pouca água armazenada, o que é confirmado pelos resultados encontrados por este trabalho.

A protrusão da raiz primária iniciou-se após 24 horas para as temperaturas de 25, 30, $20-30$ e $25-35^{\circ} \mathrm{C}$. Apenas na temperatura de $20^{\circ} \mathrm{C}$ a germinação foi iniciada ao quarto dia (Figura 1 ), demonstrando que as menores temperaturas interferem no processo de germinação, embora não tenha ocorrido diferenças na percentagem final de protusão radicular nas temperaturas de 20 e $25^{\circ} \mathrm{C}$ (Figura 2).

A germinação da espécie, distribuída entre o primeiro e o $15^{\circ}$ dia, apresentou uma distribuição temporal, com um padrão normal ou gaussiano, segundo Borghetti \& Ferreira (2004), para a maioria das temperaturas testadas.

A manutenção das sementes germinadas nas caixas transparentes, em substrato papel, mostrou-se inadequada, pois durante o processo de germinação, as primeiras plântulas formadas começaram a sofrer acelerado processo de necrose das raízes primárias, o que levou a morte das mesmas. Desta maneira, para a verificação da formação das estruturas iniciais e sua avaliação, é recomendando que logo após a germinação e a protrusão das raízes primárias, as sementes sejam retiradas e colocadas em outro substrato, tal como vermiculita. Também a utilização de outros substratos para a germinação, tais como a própria vermiculita, areia esterilizada ou agar, deveriam ser testados.

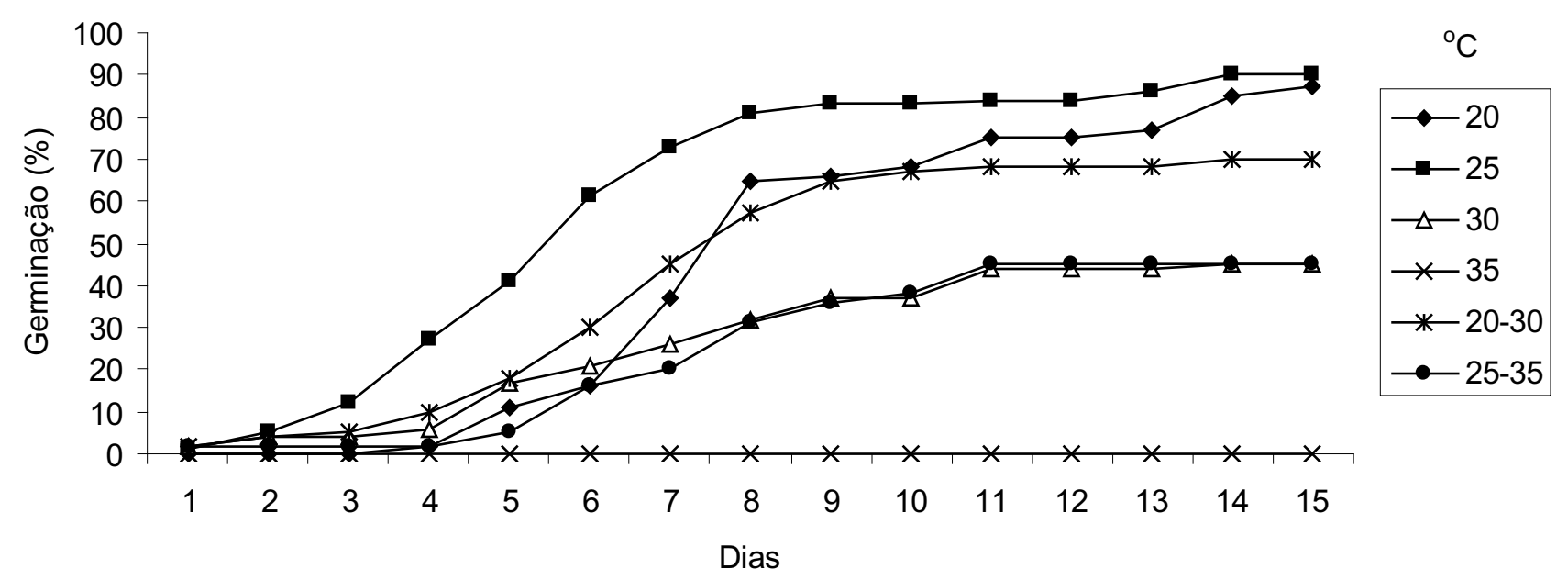

FIGURA 1. Germinação acumulada de sementes de Aspidosperma subincanum em diferentes temperaturas constantes e alternadas. 
Salomão et al. (2003) e Lorenzi (2008) informam que para esta espécie a germinação ocorre entre 15 e 30 dias, um período de tempo acima do observado para sementes coletadas na região do Pantanal, onde a protrusão da raiz primária ocorre a partir do primeiro dia, estendendose por até 14 dias. De acordo com Baskin \& Baskin (2001), as sementes, de acordo com a região de origem, podem ter diferentes comportamentos, fator relacionado a adaptação ao local ou a existência de subespécies, o que é exemplificado por Garcia et al. (2007) com sementes de Velozzia leptopetala Goeth. et Henr. e V. epidendroides Mart. ex Schult e Schult., os quais verificaram que sementes da primeira espécie germinaram melhor entre 20 e $35^{\circ} \mathrm{C}$ e a segunda, entre 30 e $40^{\circ} \mathrm{C}$, indicando que os requisitos para germinação podem ser diferentes, mesmo quando sementes de espécies do mesmo gênero são coletadas na mesma área.

A maior percentagem de germinação, considerando-se apenas as temperaturas constantes, ocorreu entre 20 e $25^{\circ} \mathrm{C}$, sendo 22,8 ${ }^{\circ} \mathrm{C}$ a temperatura ideal. Temperaturas acima das citadas não são recomendadas para a germinação dessa espécie, pois ocorre a morte da maior parte dos embriões (Figura 2). Comparando-se as temperaturas constantes e alternadas, podese observar que, mesmo por períodos de $12 \mathrm{~h}$, temperaturas mais elevadas causam uma diminuição no processo germinativo. A morte dos embriões é resultado provável de danos às estruturas das sementes através de alterações enzimáticas, por exemplo, modificando a velocidade de reações químicas, como explicado por Marcos Filho (2005) e Taiz \& Zeiger (2009) ou talvez a temperatura elevada tenha causado outro tipo de dano, também levando a morte do embrião.

Foi observado que nas temperaturas mais elevadas ocorreu uma alteração na estruturas dos cotilédones, com os carboidratos presentes adquirindo uma aparência gelatinosa, o que, de acordo com Taiz \& Zeiger (2009), seria resultado de uma embebição rápida e excessiva, podendo levar a uma hidrólise dos carboidratos, alterando sua configuração química, processo acelerado normalmente em temperaturas altas, o que talvez tenha ocorrido em parte das sementes testadas. Levando-se em consideração que as sementes testadas possuíam um baixo teor de água (4\%), talvez seja necessário um processo de préembebição, antes da colocação das sementes na câmara de germinação, para que o processo de germinação possa ocorrer em temperaturas mais elevadas.

Também deve ser levado em consideração que a época de coleta, inverno na região, é importante, pois se as sementes são dispersas em período de menor temperatura, suas taxas mais propícias de germinação também deveriam ocorrer em temperaturas mais amenas.

Temperaturas inferiores ou superiores à ótima tendem a reduzir a velocidade do processo germinativo e desta maneira, expor as plântulas a um período de tempo maior a fatores adversos (Sangalli et al., 2012), além de afetar negativamente as reações bioquímicas e a velocidade de absorção de água, levando à redução no total de germinação e/ou no tempo médio de germinação (Carvalho \& Nakagawa, 2012), provavelmente o que ocorreu nas temperaturas de $30,35,20-30$ e $25-35^{\circ} \mathrm{C}$.

Para espécies que não toleram baixas temperaturas, podem ocorrer danos quando as mesmas são expostas a este fator, gerando taxas respiratórias mais lentas, como citado por Taiz \& Zeiger (2009). Para A. subincanum foi observado para a temperatura de $20^{\circ} \mathrm{C}$, que a percentagem final de sementes germinadas foi estatisticamente igual a melhor temperatura, $25^{\circ} \mathrm{C}$ (Figura 2 ); no entanto,

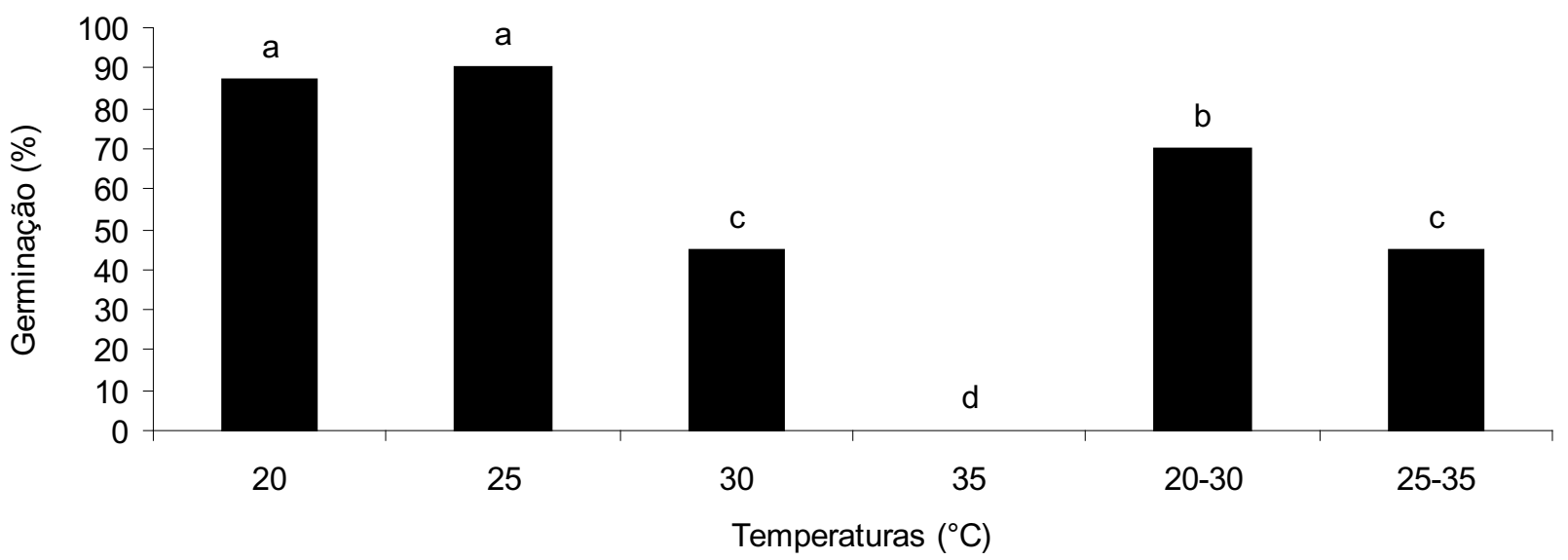

FIGURA 2. Germinação (\%) de sementes de Aspidosperma subincanum em diferentes temperaturas constantes e alternadas. As médias seguidas da mesma letra, não diferem entre si pelo teste de Tukey em $5 \%$ de probabilidade. 
a temperatura ótima é aquela que possibilita a combinação mais eficiente entre a percentagem e a velocidade de germinação e para $20^{\circ} \mathrm{C}$ foi observado os valores de IVG, 11,4 e TMG, 8,1, o que não reflete a melhor condição (Tabela 1).

Em relação às temperaturas alternadas, segundo Baskin \& Baskin (2001), sementes que respondem positivamente a este fator normalmente apresentam mecanismos enzimáticos que funcionam em diferentes temperaturas, fator provavelmente relacionado a adaptações ecológicas da espécie ao ambiente. Porém para $A$. subincanum foi observado que temperaturas alternadas não são adequadas, embora $20-30^{\circ} \mathrm{C}$ seja a segunda melhor para a velocidade de germinação. O grupo ecológico da espécie, uma planta pioneira e heliófita (Pott \& Pott, 2003), provavelmente está relacionado ao seu comportamento germinativo, pouco adaptado a alternância de temperatura. Levando-se em consideração que na região de estudo, Pantanal de Miranda, a variação de temperatura no inverno, época de coleta das sementes, entre o dia e a noite, é pequena, a menor taxa de germinação em temperaturas alternadas poderia ser explicada.

Os resultados obtidos foram similares aos apresentados por Oliveira et al. (2013) em sementes de Diptychandra aurantiaca (Mart.) Tul., com maiores taxas de germinação em temperaturas constantes, enquanto temperaturas alternadas não foram adequadas para a obtenção de uma maior percentagem de germinação. De acordo com Lorenzi (2008), essa espécie também é heliófita e comum em formações secundárias, com características ecológicas similares a $A$. subincanum, indicando as mesmas estratégias de germinação.

Com relação ao IVG (Tabela 1 ), todos os tratamentos foram estatisticamente diferentes $(F=981.3936,(p)=<0.0001)$, enquanto o TMG para as temperaturas de 30 e $25-35^{\circ} \mathrm{C}$ foram similares $(F=824.0367,(p)=0.0001)$, mas inferiores aos melhores resultados. A temperatura de $25^{\circ} \mathrm{C}$, tanto para IVG como TMG, apresentou o melhor resultado, demonstrando que além da melhor percentagem de germinação obtida, as sementes germinaram em maior quantidade no menor espaço de tempo.

Bewley \& Black (1994) e Carvalho \& Nakagawa (2012) afirmam que a melhor temperatura para a germinação se diferencia daquela que determina maior velocidade de germinação, geralmente a mais elevada. Porém esta situação não foi observada para $A$. subincanum, pois levando-se em consideração a percentagem de germinação e o vigor das sementes, medido indiretamente pelo IVG e TMG, a temperatura de $25^{\circ} \mathrm{C}$ é a mais adequada, tanto para a velocidade como para percentagem final de germinação.

Segundo Larcher (2003), a faixa ótima para a germinação de espécies de regiões tropicais está situada entre 20 e $35^{\circ} \mathrm{C}$. Embora as espécies apresentem comportamento variável em relação à temperatura, $25^{\circ} \mathrm{C}$ é considerada adequada para a maior parte das espécies do bioma Cerrado (Brancalion et al., 2010). Levando-se em consideração que a maior parte das espécies vegetais encontrada no Pantanal são oriundas do bioma Cerrado (Pott et al., 2011), a melhor temperatura encontrada está dentro do padrão esperado.

Salomão et al. (2003) relataram que para sementes de $A$. subincanum, a temperatura de $25^{\circ} \mathrm{C}$ é a mais adequada para germinação, citando valores maiores que $50 \%$. Os resultados obtidos, com as melhores taxas entre 20 e $25^{\circ} \mathrm{C}$, confirmam esta informação para $25^{\circ} \mathrm{C}$, mas não para $20^{\circ} \mathrm{C}$. Esta diferença está relacionada ao fato de que muitas espécies possuem temperatura ótima de germinação relacionada às temperaturas da região de origem das sementes, resultado de adaptações as condições locais ou a outros fatores, como época de coleta ou umidade da semente, dentre outros, que também interferem no processo de germinação. Levando-se em consideração outras espécies do

TABELA 1. Índice de velocidade de germinação (IVG) e tempo médio de germinação (TMG) de sementes de Aspidosperma subincanum submetidas a diferentes temperaturas

\begin{tabular}{ccc}
\hline Temperatura $\left({ }^{\circ} \mathrm{C}\right)$ & IVG & TMG (dias) \\
\hline 20 & $11,4 \mathrm{c}$ & $8,1 \mathrm{~d}$ \\
25 & $18,8 \mathrm{a}$ & $5,9 \mathrm{a}$ \\
30 & $9,5 \mathrm{~d}$ & $7,4 \mathrm{c}$ \\
35 & 0 & $0 \mathrm{e}$ \\
$20-30$ & $12,2 \mathrm{~b}$ & $6,8 \mathrm{~b}$ \\
$25-35$ & $8,2 \mathrm{e}$ & $7,5 \mathrm{c}$ \\
\hline
\end{tabular}

As médias seguidas da mesma letra, não diferem entre si pelo teste de Tukey em $5 \%$ de probabilidade.

Rev. Bras. PI. Med., Campinas, v.17, n.4, p.642-648, 2015. 
mesmo gênero, descritas pelos autores, como A. discolor, A. macrocarpon e A. parvifolium, que também possuem a melhor condição de germinação em $25^{\circ} \mathrm{C}$, esta temperatura parece ser um padrão para o gênero Aspidosperma.

O comportamento das espécies pode ser muito variável, quando se analisa o parâmetro temperatura para germinação. Por exemplo, Guedes \& Alves (2011), trabalhando com diferentes substratos e temperaturas para a germinação de sementes de Chorisia glaziovii (O. Kuntze) também indicaram que a temperatura de $35^{\circ} \mathrm{C}$ não era adequada e $25^{\circ} \mathrm{C}$, a melhor, com maior percentagem de germinação e IVG. Por outro lado, Lopes et al. (2005) trabalhando com sementes de Basella rubra L. indicaram às temperaturas alternadas como melhores condições de germinação. Esses resultados indicam a importância dos estudos relacionados a este parâmetro, que afeta diretamente a produção de mudas e que é muito variável, com comportamentos específicos para cada espécie.

Segundo Marcos Filho (2005), a temperatura ótima é aquela que possibilita maior percentagem e velocidade de germinação, o que foi observado para a melhor temperatura encontrada $\left(25^{\circ} \mathrm{C}\right)$. No trabalho de Oliveira et al. (2011), a maior percentagem e velocidade na germinação de sementes de $A$. tomentosum Mart., coletadas na região de Taboco, município de Corguinho, Mato Grosso do Sul, foi obtida à temperatura constante de $20^{\circ} \mathrm{C}$, indicando que na dependência da região, pode ocorrer diferenças entre o padrão encontrado entre as diferentes espécies do mesmo gênero.

A espécie $A$. subincanum distribui o processo germinativo em duas semanas e a temperatura de $25^{\circ} \mathrm{C}$ é a mais adequada para o processo de germinação. Temperaturas mais elevadas levam à morte dos embriões e não são recomendadas; após a germinação, não deve-se manter as sementes no substrato papel, pois ocorre uma rápida necrose das raízes primárias, levando a morte das plântulas.

\section{AGRADECIMENTO}

Os autores agradecem a Universidade Anhanguera-Uniderp o financiamento do projeto GIP (Grupo Interdisciplinar de Pesquisa) e pela bolsa de iniciação cientifica concedida (PIC) e também ao Conselho Nacional de Desenvolvimento Científico e Tecnológico (CNPq), pelas bolsas de Iniciação Científica (PIBIC) e de Produtividade em Pesquisa concedidas. Também agradecem aos pareceristas pelas sugestões e críticas.

\section{REFERÊNCIAS}

BASKIN, C.C.; BASKIN, J.M. Seeds: ecology, biogeography, and evolution of dormancy and germination. San Diego, Academic Press, 2001. 666p.

BERNARDES, M.J. et al. Hypotensive effect of Aspidosperma subincanum Mart. in rats and its mechanism of vasorelaxation in isolated arteries. Journal of Ethnopharmacology, v.145, n.1, p.22732, 2013.

BEWLEY, J.D.; BLACK, M. Seeds: physiology of development and germination. 2ed. New York and London: Plenum Press, 1994. 445p.

BORGHETTI, F.; FERREIRA, A.G. Interpretação de resultados de germinação. In: FERREIRA, A.G.; BORGHETTI, F. (Eds). Germinação: do básico ao aplicado. Porto Alegre: Artmed. p.209-222. 2004.

BRANCALION, P.H.S. et al. Temperatura ótima de germinação de sementes de espécies arbóreas brasileiras. Revista Brasileira de Sementes, v.32, n.4, p.15-21, 2010.

BRASIL. Ministério da Agricultura, Pecuária e Abastecimento. Regras para análise de sementes. Brasília: Secretaria de Defesa Agropecuária, 2009. 395p.

CARVALHO, N.M.; NAKAGAWA, J. Sementes: ciência, tecnologia e produção. 5ed. Jaboticabal: FUNEP, 2012. 590 p.

GARCIA, Q.S. et al. Resposta germinativa de duas espécies de Vellozia (Velloziaceae) dos campos rupestres de Minas Gerais, Brasil. Acta Botanica Brasilica, v.21, n.2, p.451-456, 2007.

GUEDES, R.S.; ALVES, E.U. Substratos e temperaturas para o teste de germinação de sementes de Chorisia glaziovii (O. Kuntze). Cerne, v.17, n.4, p.525-531, 2011.

LABOURIAU, L.G.; AGUDO, M. On the physiology of seed germination in Salvia hispanica L. I Temperature effects. Anais da Academia Brasileira de Ciências, v.59, n.1, p.37-50, 1987.

LARCHER, W. Physiological plant ecology: ecophysiology and stress physiology of functional groups. Berlin: Springer, 2003. 533p.

LOPES, J.C. et al. A. Influência de temperatura, substrato e luz na germinação de sementes de Bertalha. Revista Brasileira de Sementes, v.27, n.2, p.18-24, 2005.

LORENZI, H. Árvores brasileiras: manual de identificação e cultivo de plantas arbóreas nativas do Brasil. v. 1. 5ed. Nova Odessa: Plantarum, 2008. 384p.

MAGUIRE, J.D. Speed of germination aid in selection and evaluation for seedling and vigour. Crop Science, v.2, n.1, p.176-177, 1962.

MARCOS FILHO, J. Fisiologia de sementes de plantas cultivadas. Piracicaba: FEALQ, 2005. 495p.

MONTELES, R.; PINHEIRO, C.U.B. Plantas medicinais em um quilombo maranhense: uma perspectiva etnobotânica. Revista Biologia e Ciências da Terra, v.7, n.2, p.38-48, 2007.

OLIVEIRA, A.K.M. et al. Germinação de sementes de Aspidosperma tomentosum Mart. (Apocynaceae) em diferentes temperaturas. Revista Brasileira de Biociências, v.9, n.3, p.392-397, 2011.

OLIVEIRA, A.K.M. et al. Effects of temperature on the

Rev. Bras. PI. Med., Campinas, v.17, n.4, p.642-648, 2015. 
germination of Diptychandra aurantiaca (Fabaceae) seeds. Acta Scientiarum. Agronomy, v.35, n.2, p.203-208, 2013.

PIÑA-RODRIGUES, F.C.M.; FIGLIOLIA, M.B.; PEIXOTO, M.C. Testes de qualidade. In: FERREIRA, A.G.; BORGHETI, F. Germinação: do básico ao aplicado. Porto Alegre: Artmed. p.283-297. 2004.

POTT, A. et al. Plant diversity of the Pantanal wetland. Brazilian Journal of Biology, v.71, n.1, p.265-273, 2011.

POTT, A.; POTT, V.J. Plantas Nativas potenciais para sistemas agroflorestais em Mato Grosso do Sul. In: Seminário Sistemas Agroflorestais e Desenvolvimento Sustentável. Campo Grande: Embrapa-CNPGC, 2003. CD-ROM.

SALOMÃO, A.N. et al. Germinação de sementes e produção de mudas de plantas do cerrado. Brasília: Rede de sementes do Cerrado, 2003. 96p.

SANGALLI, A. et al. Morfometria de frutos e sementes e germinação de carobinha (Jacaranda decurrens subsp. symmetrifoliolata Farias \& Proença), após o armazenamento. Revista Brasileira de Plantas Medicinais, v.14, n.2, p.267-275, 2012.

SANTOS, S.R. et al. Toxicological and phytochemical studies of Aspidosperma subincanum Mart. stem bark (Guatambu). Die Pharmazie - An International Journal of Pharmaceutical Sciences, v.64, n.12, p.836-839, 2009.

SILVA, M.A.B. Levantamento etnobotânico e triagem hipolipidêmica de plantas medicinais do Cerrado matogrossense: avaliação da atividade hipolipidêmica da Simaba ferruginea St. Hil. e Vochysia rufa Mart. Cuiabá, 166f. Dissertação de mestrado, Faculdade de Ciências Médicas, Universidade Federal de Mato Grosso, 2009.

TAIZ, L.; ZEIGER, E. Fisiologia vegetal. 4ed. Porto Alegre: Artmed, 2009. 719p.

TRESVENZOL, L.M.F. et al. Levantamento das plantas medicinais do estado de Goiás. IV Encontro de Pesquisadores da UFG; Goiânia, Brasil, 1997. 